\title{
Study on Abandoning Wind Power in China
}

\author{
Tao Liu \\ School of North China Electric Power University, Hebei 071003, China \\ 1303551336@qq.com
}

Keywords: wind power generation, abandoned wind power rationing, analysis of abandoning wind power.

\begin{abstract}
The development of new energy sources such as wind energy is an important part of the world. However, the overwhelming majority of accumulated and added installment is now embarrassing China's wind power by grid connectivity and power curtailment problems. This paper analyzes the causes of abandonment from the three aspects of wind resource characteristics, current situation of distribution facilities and management mechanism, and the situation of abandonment in the Northeast, North and Northwest China area in 2011.
\end{abstract}

\section{Introduction}

Although wind turbines are under normal circumstances, the lack of local power grid capacity and wind power instability and other characteristics lead some of the turbine wind farm to suspend operation. That is the so-called abandoning wind power.

China's wind power industry in recent years has developed rapidly, but the problem of abandoned wind power rationing is prominent. The issue of abandoning the wind has become more and more serious, the national average rate of abandonment for a long time higher than $10 \%$ from 2010 . Abandoning wind power generation in Inner Mongolia caused large economic losses amounting to more than one billion Chinese Yuan (158 million US dollar) in 2011 [1]. It is estimated that from 2010 to 2015 , the cumulative amount of wind power reached 99.7 billion $\mathrm{KWh}$, the direct economic losses have been more than 53 billion Yuan. This paper analyzes the problem of abandonment and wind restriction from many angles in 2011 as a typical year.

\section{Wind Power Curtailment Condition}

\subsection{The Situation of Abandoning the Wind in 2011}

Many wind turbines were shut down when the excess electricity occurred and as the coal-dominated energy supply system was rigid, part of the coal-fired power plants had to operate continuously in order to secure the grid stabilization [2]. In 2011, China abandoned wind power capacity more than 10 billion $\mathrm{KWh}$, the northwest and the northeast region abandoned wind reached $20 \%$, some areas of wind power utilization hours down to $1600 \mathrm{~h}$ (1900h is the breakeven point). It can be roughly estimated that last year there were about 10 billion KWh of wind power in the country due to the loss of electricity generation, which is equivalent to the loss of more than 3 million 300 thousand tons of standard coal. 
Table 1. The main provinces' ranking of abandoned wind in 2011

\begin{tabular}{|c|c|c|c|c|c|}
\hline Ranking & province & $\begin{array}{c}\text { Installed } \\
\text { capacity(Million } \\
\text { kilowatts) }\end{array}$ & $\begin{array}{c}\text { New grid } \\
\text { capacity(Million } \\
\text { kilowatts) }\end{array}$ & $\begin{array}{c}\text { The mount of } \\
\text { abandoning } \\
\text { wind(Billion } \\
\text { KWh) }\end{array}$ & $\begin{array}{c}\text { The percent of } \\
\text { abandoning wind } \\
\text { power (\%) }\end{array}$ \\
\hline 1 & Gansu & 568.44 & 60.73 & 10.94 & 25.25 \\
\hline 2 & $\begin{array}{c}\text { Inner } \\
\text { Mongolia }\end{array}$ & 1624.44 & 426.59 & 32.87 & 23.10 \\
\hline 3 & Jilin & 317.64 & 30.00 & 4.75 & 21.02 \\
\hline 4 & Heilongjiang & 277.55 & 52.99 & 4.48 & 14.39 \\
\hline 5 & Liaoning & 469.26 & 57.75 & 3.90 & 10.45 \\
\hline 6 & Xinjiang & 226.43 & 73.80 & 0.70 & 5.20 \\
\hline 7 & Yunnan & 93.23 & 63.71 & 0.24 & 4.90 \\
\hline 8 & Hebei & 607.53 & 411.30 & 1.78 & 3.86 \\
\hline 9 & Shandong & 382.11 & 74.70 & 0.10 & 1.17 \\
\hline 10 & Guangdong & 130.23 & 31.50 & 0.04 & 0.64 \\
\hline
\end{tabular}

Source: National Energy Board, CREIA, CWEA and so on

\subsection{A Brief Description of the Situation from 2010 to 2015}

Nearly five years the average rate of abandoned winds reached $13.4 \%$, the loss of electricity fees accumulated about 51.8 billion yuan. From the statistical point of view, China's cumulative loss of abandoned wind power reached 95.9 billion kwh from 2011 to 2015. Among them, the most serious winds occurred in 2012, the rate of abandoned wind has reached $17 \%$. After a series of government policy guidance and industry initiative to adjust, the phenomenon of abandoned wind in 2013 has eased, that rate dropped to $11 \%$ and in 2014 to $8 \%$. In 2015, by the impact of various economic factors, abandoned wind rate soared to $15 \%$ once again. Due to the substantial increase in installed capacity, abandoned wind power also rose sharply in 2015. According to official statistics, China's wind power abandoned in 2011 for the first time over 10 billion KWh and more than doubled in 2012, although the rate of abandoned wind decline in 2013 and 2014, but the capacity of abandoned wind power remains at 10 billion $\mathrm{KWh}$ above.
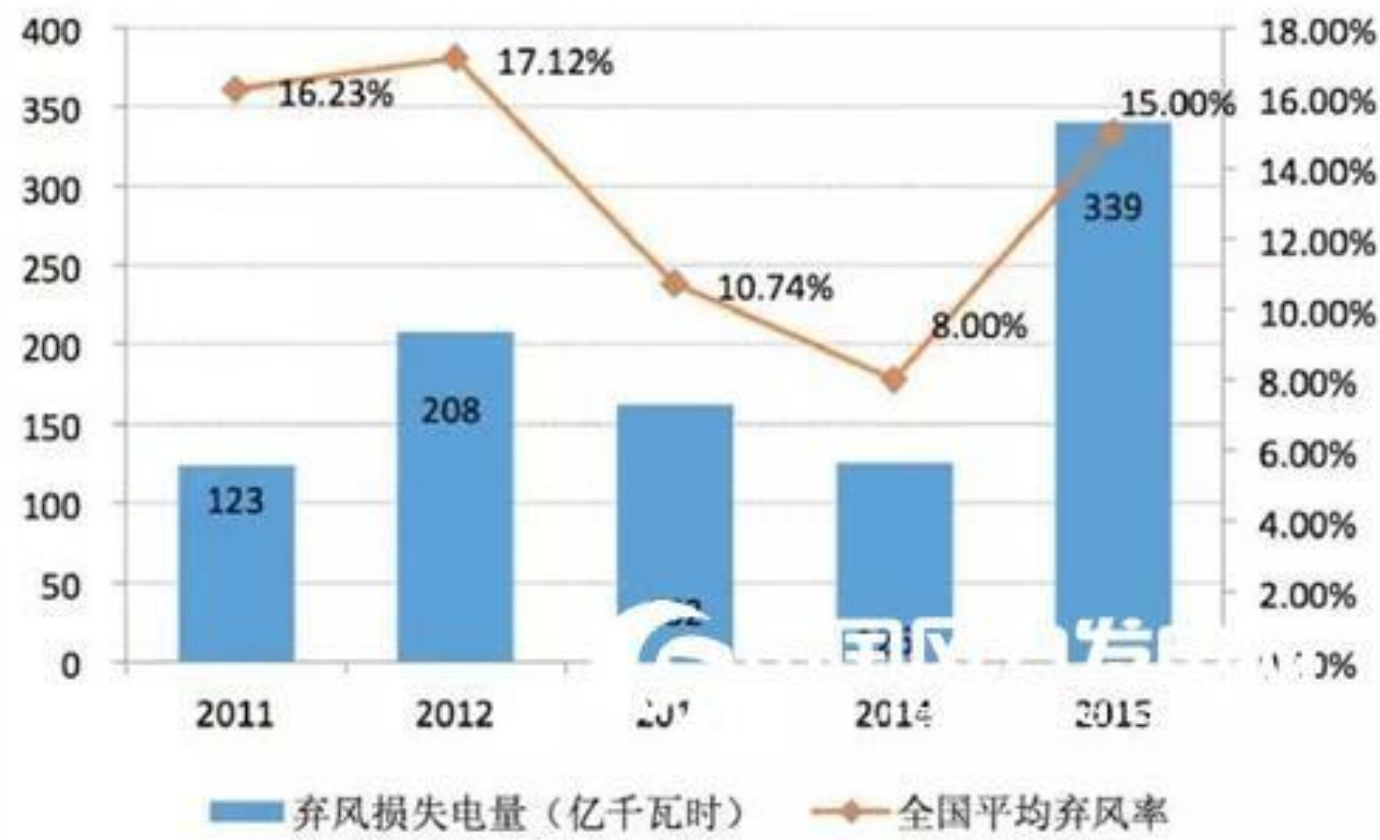

Fig. 1 a brief description of the situation from 2010 to 2015 
Source: www.fenglifadian.com

\section{Reason for Abandoning the Wind.}

Wind power is a kind of pollution-free energy, in the premise of priority scheduling, when the problem of system coordination and balance occurs, the abandoned wind phenomenon will appear. But with the abandonment of the wind gradually become the focus of attention, defects of management are gradually highlighted. The reasons for the occurrence of the wind are divided into the following three:

\subsection{Uncertainty of Wind Resources}

Wind power is different from the conventional energy generation methods such as thermal power. The wind power generation has the characteristics of randomness, large fluctuation and low predictability. At the same time, wind power is a less reliable power supply, wit small possibility of high power [3].

\subsection{Wind Farm Construction and Delivery Capacity Is Not Balanced}

Most of the wind farms are built in the rich areas of wind resources, the geographical location is often more remote, at the end of the grid, and the distribution structure is relatively weak [4]. Electric power dispatching agencies can not send out the power generation, but also can not be local consumption, so only by controlling the wind power output to ensure the normal operation of the grid.

\subsection{Management System}

The development of wind power has touched on the institutional arrangements of the traditional electricity market [5]. Under the existing electricity system, the thermal power is based on the planned electricity generation capacity developed by the electric power department, and has achieved the de facto power of priority, narrowing the development space of new energy such as wind power.

\section{Conclusion}

As we can see from situation over the years, the abandoned wind rate has been high, the short term to solve the abandoned wind phenomenon is almost impossible. The wind power industry still maintained a strong momentum of growth, if governments do not take the necessary measures, the economic loss and energy loss will be more and more.

\section{References}

[1]. Liu G, Zhang X. Inner Mongolia has to abandon wind power production in the heating period; 2011.

[2]. Wen Liu, Weihao Hu, Henrik Lund, Zhe Chen Electric vehicles and large-scale integration of wind power - The case ofInner Mongolia in China 2012

[3]. Han ZiFen, YAO ZHI Zong ,JIAHuai Sen, LU Liang, Wang JianDong, Wang DingMei, PANG Weil, HE Min Study on Calculation Methods of Wind Farm's Abandoned Energy 2011

[4]. Herbert Inhaber * Risk Concepts, 3920 Mohigan Way, Las Vegas, NV 89119, United States Why wind power does not deliver the expected emissions reductions 2011

[5]. Wang Yan*, Shi Jinwei State Key Laboratory of Alternate Electrical Power System with Renewable energy Sources North China Electric Power University Baoding, China Study on Wind Power Consumption Based on Demand Response 2012 